\title{
Evaluation of musculoskeletal adverse effects in patients on systemic isotretinoin treatment: A cross-sectional study
}

\author{
Emine Müge $\operatorname{Acar}^{1}\left(\mathbb{D}\right.$, Senem Şaş ${ }^{\mathbb{D}}$, Fatmanur Aybala Koçak ${ }^{3}$ D \\ ${ }^{1}$ Department of Dermatology and Venerology, Kırşehir Training and Research Hospital, Kırşehir, Türkiye \\ ${ }^{2}$ Department of Physical Therapy and Rehabilitatiton, Erciyes University Faculty of Medicine, Kayseri, Türkiye \\ ${ }^{3}$ Department of Physical Therapy and Rehabilitatiton, Ahi Evran University Faculty of Medicine, Kırşehir, Türkiye
}

\begin{abstract}
Objectives: This study aims to investigate the frequency of musculoskeletal adverse effects in acne vulgaris patients receiving systemic isotretinoin treatment.

Patients and methods: Between January 2016 and December 2017, a total of 200 severe acne patients (22 males, 178 females; mean age: $21.8 \pm 0.4$ years; range, 15 to 53 years) who were on isotretinoin treatment were retrospectively analyzed. Data including age, sex, body mass index (BMI), duration of disease, diagnosis, and comorbidities were recorded. Back pain severity was evaluated with the Visual Analog Scale (VAS).

Results: The treatment period was mean $8.5 \pm 0.1$ (range, 6 to 12 ) months. The dose of isotretinoin was mean $0.6 \pm 0.1$ (range, 0.5 and 1 ) $\mathrm{mg} / \mathrm{kg}$. Musculoskeletal side effects were seen in 99 (49.5\%) patients. Back pain was reported during the treatment period in 78 (78.7\%) patients. The diagnosis was mechanical back pain in 31 (39.7\%) and inflammatory back pain in 47 (60.3\%) patients. The moderate-severe back pain group received higher cumulative isotretinoin doses than the mild back pain group $(p=0.003)$. The BMI values did not show a significant difference between the patients with and without back pain $(p=0.55)$. There was no significant correlation between the BMI and VAS scores $(p=0.06)$. The VAS scores were found to be correlated with age $(p=0.04)$. Sacroiliitis was diagnosed in four $(4 \%)$ patients. One $(1 \%)$ patient was diagnosed with enthesitis. Creatine kinase elevation was reported in $18(18.1 \%)$ patients, while three (3\%) patients described myalgia of mild severity.

Conclusion: Low back pain is one of the most common musculoskeletal side effects of isotretinoin treatment that usually resolves with dose reduction. The cumulative dose of isotretinoin does not seem to play a role in the development of back pain, but can determine pain severity. Pain severity is directly correlated with the increasing age. Evaluation of the patients for musculoskeletal side effects during isotretinoin use is important in clinical practice, as it is a common occurrence.

Keywords: Acne, hyperostosis, inflammatory back pain, sacroiliitis, spondyloarthropathy, systemic isotretinoin.
\end{abstract}

Acne vulgaris is a chronic inflammatory skin disease, particularly affecting the young population. Topical and systemic treatment regimens are used to treat the condition. Isotretinoin is a synthetic vitamin $\mathrm{A}$ derivative that is effective on four of the factors that play a role in acne pathogenesis: sebum hypersecretion, follicular hyperkeratinization, Propionibacterium acnes proliferation, and inflammation. ${ }^{1}$ It affects acne pathogenesis by binding to cellular retinol binding protein or retinoic acid nuclear receptors. ${ }^{2}$

Isotretinoin use is associated with mucocutaneous, ocular, neurological, musculoskeletal, and hepatic side effects. Musculoskeletal side effects are common during systemic isotretinoin treatment and include

Received: December 11, 2020 Accepted: August 23, 2021 Published online: December 24, 2021

Correspondence: Emine Müge Acar, MD. Kırşehir Eğitim ve Araştırma Hastanesi Dermatoloji ve Veneroloji Kliniği, 40200 Özbağ, Kırşehir, Türkiye. Tel: +90386 - 2134515 e-mail: drmugeacar@gmail.com

\section{Citation:}

Acar EM, Şaş S, Aybala Koçak F. Evaluation of musculoskeletal adverse effects in patients on systemic isotretinoin treatment: A cross-sectional study. Arch Rheumatol 2022;37(2):223-229. 
enthesopathy, arthritis, sacroiliitis, costochondritis, osteoporosis, hyperostosis, extraspinal calcifications, and premature epiphyseal closure in children. ${ }^{3-10}$

Isotretinoin has detergent-like properties and can affect immunomodulation by causing alterations in the cytokine levels. ${ }^{11,12}$ The activation of matrix metalloproteinases (MMPs) which is stimulated by proinflammatory cytokines is known to play a role in the pathogenesis of osteoarthritis and rheumatoid arthritis. ${ }^{13}$ Retinol and retinoic acid have been shown to induce MMP-2 activity. ${ }^{14}$ The same mechanism may also play a role in the development of side effects such as sacroiliitis and tendinitis during isotretinoin treatment. Catabolic events such as the upregulation of ubiquitin ligases including atrogin- 1 and muscle-specific ring finger protein-1 have been also noted in the etiology of muscle pain related to isotretinoin. ${ }^{15,16}$

The results of the limited number of studies investigating the frequency of isotretinoin-related musculoskeletal effects in the literature have been variable. , $^{, 417-19}$ Myalgia, arthralgia, and low back pain have been reported as the most common musculoskeletal side effects. ${ }^{3,17,19}$ Sacroiliitis has been reported in $8.2 \%$ and $11.7 \%$ of the patients, respectively, in two different studies. ${ }^{3,19}$ Tendinopathy is another side effect, but it is less common. Tendinopathy has been reported in $4.3 \%$ of the patients in the study of Karaosmanoğlu and Mülkoğlu. ${ }^{19}$

The management of the musculoskeletal side effects related to isotretinoin use is important, as these side effects are frequently encountered in clinical practice. In the present study, we aimed to evaluate the frequency and sex distribution of these musculoskeletal side effects and to examine the effect of age, drug dose, and body mass index (BMI) on isotretinoin treatment.

\section{PATIENTS AND METHODS}

This single center, cross-sectional, retrospective study was conducted at Kırşehir Training and Research Hospital, Department of Dermatology between January 1 ${ }^{\text {st }}, 2016$ and December $31^{\text {st }}$, 2017. A total of 200 severe acne patients (22 males, 178 females; mean age:
$21.8 \pm 0.4$ years; range, 15 to 53 years) who were initiated on isotretinoin treatment were included (Table 1). Patients with a history of neuromuscular, rheumatoid, or systemic inflammatory disease were excluded. The patients on isotretinoin were referred to the Physical Medicine and Rehabilitation specialist during their monthly follow-up and the development of any musculoskeletal side effects was evaluated. The data of these patients were retrospectively analyzed together with the radiology findings.

Data including age, sex, height, weight, BMI, duration of disease, diagnosis, and comorbidities of the patients were recorded. The BMI $\left(\mathrm{kg} / \mathrm{m}^{2}\right)$ was calculated. Pain was evaluated with the Visual Analog Scale (VAS) as 0 to 10. The VAS scores of 1-4 were classified as mild pain, 5-6 as moderate pain, and 7-10 as severe pain. ${ }^{20}$

Inflammatory low back pain was evaluated using the Assessment of Spondyloarthritis international Society (ASAS) criteria. The ASAS criteria consist of disease onset under the age of 40 years, insidious onset, relief with exercise, no relief with rest, and nocturnal pain improving with rising. ${ }^{21}$

\section{Statistical analysis}

Statistical analysis was performed using the IBM SPSS version 21.0 software (IBM Corp., Armonk, NY, USA). Descriptive data were expressed in mean \pm standard deviation (SD), median (min-max) or number and frequency, where applicable. The statistical difference between the groups was analyzed using the Student t-test for mean values. The correlation between the variables was evaluated using the Spearman correlation test. A $p$ value of $<0.05$ was considered statistically significant.

\section{RESULTS}

The treatment period was mean $8.5 \pm 0.1$ (range, 6 to 12) months. The dose of isotretinoin was mean $0.6 \pm 0.1$ (range, 0.5 and 1) mg/kg. Musculoskeletal side effects were seen in 99 (49.5\%) patients. Seventy-eight (78.7\%) patients, including 12 males (15.4\%) and 66 females (84.6\%), described back pain during the treatment period. The number of female patients with back pain was significantly higher than the male 


\begin{tabular}{|c|c|c|c|}
\hline & Male & Female & Total \\
\hline & Mean \pm SD & Mean \pm SD & Mean \pm SD \\
\hline Age (year) & $20.5 \pm 0.6$ & $22.0 \pm 0.4$ & $21.8 \pm 0.4$ \\
\hline Treatment duration (month) & $4.7 \pm 1.2$ & $5.1 \pm 0.1$ & $5.1 \pm 0.107$ \\
\hline Isotretinoin dosage (mg) & $4745 \pm 310$ & $4610 \pm 120$ & $4630 \pm 110$ \\
\hline BMI & $21.4 \pm 1.7$ & $21.7 \pm 1.6$ & $21.6 \pm 0.1$ \\
\hline
\end{tabular}

patients $(p=0.001)$. The rate of developing back pain was higher in the male patients than in the female patients, although the difference was not statistically significant $(p=0.089)$. Thirty-one patients (39.7\%), including eight males and 23 females, were diagnosed with mechanical back pain and 47 (60.3\%) patients, including four males and 43 females, with inflammatory back pain. The ratio of the female patients developing inflammatory back pain was significantly higher than the male patients $(p=0.041)$ (Table 2$)$.

Considering the severity of back pain, 49 (62.8\%) patients had mild, 23 (29.5\%) patients had moderate, and six (7.7\%) patients had severe pain. There was no significant correlation between the treatment duration, cumulative isotretinoin dosage, and the VAS score $(p=0.47, p=0.09$, $p=0.45$, respectively). However, the mean cumulative isotretinoin dose in the moderate and severe back pain groups was significantly higher than in the mild back pain group $(p=0.003)$. There was a significant correlation between the VAS score and age $(p=0.04)$. However, the mean VAS score was not statistically significantly different between the sexes $(p=0.088)$. The mean BMI value of the patients with back pain was not statistically significantly different than those without back pain $(p=0.55)$, and there was no significant correlation between the VAS score and the BMI $(p=0.06)$ (Table 3).

Dose reduction was used in patients with moderate and severe back pain, constituting 37.2\%

Table 2. Isotretinoin related side effects according to sex

\begin{tabular}{|c|c|c|c|c|c|c|c|}
\hline & \multicolumn{2}{|c|}{ Male } & \multicolumn{2}{|c|}{ Female } & \multicolumn{2}{|c|}{ Total } & \multirow[b]{2}{*}{$p$} \\
\hline & $\mathrm{n}$ & $\%$ & $\mathrm{n}$ & $\%$ & $\mathrm{n}$ & $\%$ & \\
\hline Back pain & 12 & 15.4 & 66 & 84.6 & 78 & 77.2 & $0.00^{*}$ \\
\hline Inflammatory & 4 & 8.5 & 43 & 91.5 & 47 & 39.7 & $0.00^{*}$ \\
\hline Mechanical & 8 & 25.8 & 23 & 74.2 & 31 & 60.3 & $0.00^{*}$ \\
\hline Back pain severity & & & & & & & $0.00^{*}$ \\
\hline Mild & 9 & 18.4 & 40 & 81.6 & 49 & 62.8 & \\
\hline Moderate & 3 & 13.0 & 20 & 87 & 23 & 29.5 & \\
\hline Severe & - & - & 6 & 100 & 6 & 7.7 & \\
\hline Sacroiliitis & 1 & 25 & 3 & 75 & 4 & 4 & 0.25 \\
\hline Enthesitis & - & - & 1 & 100 & 1 & 1 & - \\
\hline Myalgia & 1 & 33.3 & 2 & 66.7 & 3 & 3 & 0.33 \\
\hline CK elevation & 13 & 86.7 & 2 & 13.3 & 15 & 14.8 & 0.1 \\
\hline
\end{tabular}


Table 3. Correlation coefficents and significance values of VAS and age, cumulative isotretinoin dosage, treatment duration and BMI

\begin{tabular}{ll}
\hline Variables & VAS \\
\hline Age & \\
Correlation coefficent & 0.26 \\
$p$ & $0.04^{*}$ \\
Cumulative isotretinoin dosage & \\
$\quad$ Correlation coefficent & 0.09 \\
$p$ & 0.45 \\
Treatment duration & \\
Correlation coefficent & 0.02 \\
$p$ & 0.47 \\
Body mass index & \\
Correlation coefficent & 0.20 \\
$p$ & 0.06 \\
\hline
\end{tabular}

VAS: Visual Analog Scale; BMI: Body mass index; * $p<0.05$ was considered statistically significant.

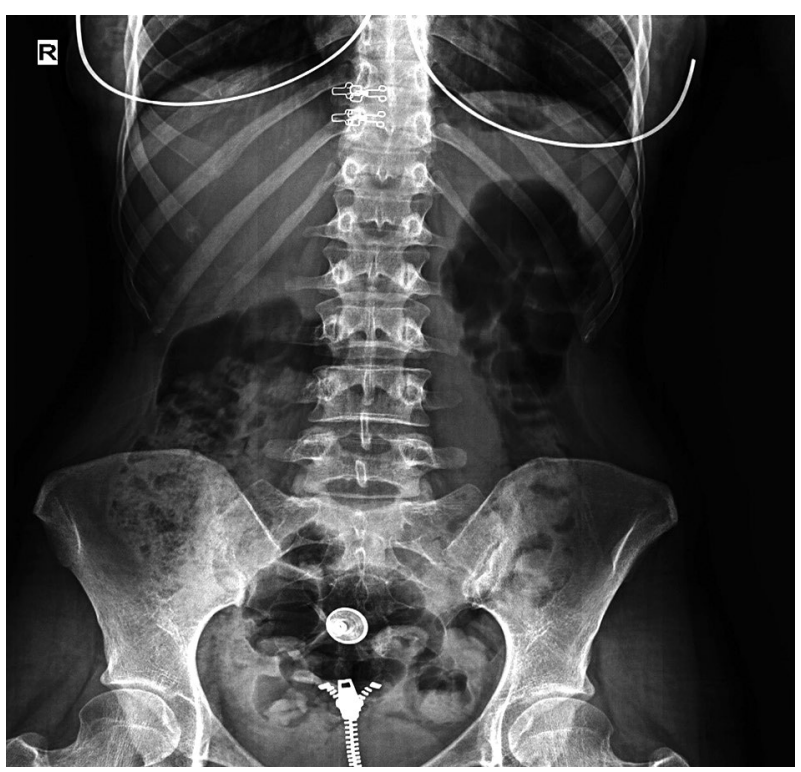

Figure 1. Bilateral sacroiliitis in pelvic X-ray.



Figure 2. Enthesitis in right side of lateral foot X-ray. of the patients describing the complaint. The vast majority of these patients responded to dose reduction, while eight (10.2\%) patients needed to use non-steroidal anti-inflammatory drugs for pain relief. Sacroiliitis was present in four (4\%) patients, including three females and one male. There was no statistically significant difference between the sexes for sacroiliitis development $(p=0.25)$. Bilateral sacroiliitis was detected in one patient (Figure 1). Sacroiliitis regressed 1.5 to 2.5 months after isotretinoin treatment cessation in all patients. The patients diagnosed with sacroiliitis were followed for six months. Three (3\%) patients described myalgia, which was of mild severity and did not require additional treatment. Among these patients, two female patients also described low back pain. Creatine kinase $(\mathrm{CK})$ elevation was observed in 18 (18.1\%) patients, including 13 males and two females, one to three months after the beginning of treatment $(p=0.1)$. The elevated CK values ranged between 233 and $940 \mathrm{IU}$ and returned to normal levels after dose reduction. One (1\%) female patients who was on low-dose isotretinoin treatment $(0.5 \mathrm{mg} / \mathrm{kg})$ was diagnosed with enthesitis at three months of treatment (Figure 2).

\section{DISCUSSION}

Isotretinoin use is associated with neuromuscular side effects, the most common of which are musculoskeletal pains and arthralgia. These side effects are seen in $20 \%$ of patients. They are usually mild and improve with discontinuation of treatment. ${ }^{3,7}$

In the current study, the most common musculoskeletal side effect was back pain. Our results are in line with previous studies, suggesting a high rate of mechanical and inflammatory back pain in patients using isotretinoin. ${ }^{3,17,19}$ Türkmen ${ }^{22}$ reported that back pain in patients using isotretinoin was more common in females. However, there was a higher percentage of male patients developing back pain in the current study.

Karaosmanoğlu and Mülkoğlu ${ }^{19}$ reported low back pain in $70.2 \%$ of isotretinoin users (inflammatory in 37.8\% and mechanical in 62.2\%). Similarly, Baykal Selçuk et al. ${ }^{3}$ reported a higher percentage of mechanical back pain $(27.3 \%)$ than inflammatory back pain (21.9\%). In contrast, 
the current study revealed a higher frequency of inflammatory back pain, similar to the study by Taheri et al. ${ }^{17}$ where $54.7 \%$ and $45.3 \%$ of the patients experienced inflammatory low back pain and mechanical low back pain, respectively. Inflammatory low back pain was more common in the female population in our study. Similarly, Elnady et al. ${ }^{23}$ reported that $70.7 \%$ of the patients developing inflammatory back pain were female.

In the literature, only a few studies have investigated the predisposing factors for the development of back pain related to isotretinoin use. Karaosmanollu and Mülkoğlu ${ }^{19}$ reported that patients with back pain received higher doses of isotretinoin than the group without back pain. In our study, we found no significant difference in terms of the cumulative isotretinoin dose between the patient groups with and without back pain. This finding indicates that the development of back pain may not be dependent on the isotretinoin dose. There was also no significant correlation between VAS score and the cumulative dose. However, the moderate and severe pain group received a higher cumulative isotretinoin dose than the mild pain group, suggesting that the severity of the back pain could be affected by the cumulative dose. This is also supported by the fact that the pain severity decreases with isotretinoin dose reduction in most patients.

Obesity has been associated with an increased risk of low back pain in some studies. ${ }^{24,25}$ Increased BMI values were not an additional risk factor for the development or increased pain severity in the current study. However, since patients with high BMI values $\left(>25 \mathrm{~kg} / \mathrm{m}^{2}\right)$ constituted a small proportion of our cohort, further large-scale studies including patients with and without obesity and using isotretinoin are warranted.

In our study, the correlation between the VAS scores and age suggests that the effect of isotretinoin on the musculoskeletal system increases with age. Musculoskeletal degeneration related to alterations in hormones, cytokines, growth factors, and altered connective tissue biology occurs during the aging process. ${ }^{26}$ Therefore, older patients may be more likely to develop more severe musculoskeletal side effects related to isotretinoin.

Sacroiliitis is the inflammation of the sacroiliac joint and can be seen as a component of various rheumatic diseases including psoriatic arthropathy, familial Mediterranean fever, and Behçet's disease. ${ }^{27,28}$ Acute sacroiliitis can also develop secondarily to hyperparathyroidism, gout, calcium pyrophosphate dihydrate deposition, infectious factors such as brucellosis, hematological malignancies, and intravenous drug use. ${ }^{28}$ In this study, the patients having a history of such diseases associated with sacroiliitis were excluded. Isotretinoin-induced sacroiliitis develops days to weeks after starting the treatment. ${ }^{29}$ The presence of human leukocyte antigen-B27 (HLA-B27) may also pose a tendency toward the development of sacroiliitis during isotretinoin treatment. ${ }^{30}$ In a study by Baykal Selçuk et al., ${ }^{3}$ the prevalence of sacroiliitis during isotretinoin use was found to be $8.2 \%$ and the symptoms developed within the first two to three months of isotretinoin treatment. In the current study, sacroiliitis developed within the first one to six months of isotretinoin treatment. Similar to the study by Baykal Selçuk et al., ${ }^{3}$ there was no significant difference between both sexes in terms of sacroiliitis development. Another study reported that sacroiliitis related to isotretinoin treatment was more frequent in females than males. ${ }^{23}$ Since the number of patients diagnosed with sacroiliitis is low in our study, future studies with larger series would be more helpful in determining the sex predominance for sacroiliitis development during isotretinoin treatment.

Previous studies provide insufficient data to assume that sacroiliitis development is dosedependent. Karadağ et al. ${ }^{29}$ reported sacroiliitis in four patients undergoing isotretinoin treatment at a dose of $0.5 \mathrm{mg} / \mathrm{kg}$. The patients developing sacroiliitis in our study were also on a low dose of isotretinoin, supporting the notion that sacroiliitis development is not dose-dependent. The lower rate of sacroiliitis in the current study can be attributed to the careful selection of patients with no prior history of arthritis or arthralgia, as well as the heterogeneity of the genetic features of the study populations that can determine the susceptibility for the development of sacroiliitis. In our study, symptoms completely regressed with treatment cessation in all patients with sacroiliitis.

Muscular side effects including myalgia and muscle stiffness have been reported in 15 to 50\% of patients treated with isotretinoin. ${ }^{18,31,32}$ Myalgia associated with isotretinoin use is usually mild. ${ }^{3}$ 
Elevation of CK levels, which indicates serious muscular cell damage, has been reported in 5.6 to $41 \%$ of the patients with isotretinoin use. ${ }^{33}$ The elevations in CK have been mostly reported to be detected incidentally on routine blood tests of the patients, with no concurrent clinical symptoms. ${ }^{31-35}$ In a study by Kaymak ${ }^{18}$ including 89 patients on isotretinoin treatment, five patients had elevated CK levels and only one patient had myalgia. The main features of $\mathrm{CK}$ elevation include darker skin types, male sex, and a history of regular athletic activity. ${ }^{18}$ Male patients constituted the majority in our study, and all had a history of vigorous physical activity. Elevated CK levels (approaching or exceeding 1,000 to $2,500 \mathrm{IU}$ ) during isotretinoin treatment also raise a concern for rhabdomyolysis, which is characterized by generalized muscle damage, acute kidney injury, and myoglobinuria. ${ }^{33}$ Severe acute myopathy has also been reported in two patients on isotretinoin treatment in the literature..$^{36}$ in the present study, we observed no rhabdomyolysis, renal failure, or myopathy in any of the patients.

Enthesopathy is a reported side effect of isotretinoin and usually develops after long-term isotretinoin use. ${ }^{37,38}$ However, cases associated with short-term isotretinoin treatment have also been reported in the literature. Tendinitis of the Achilles tendon is a known side effect of isotretinoin and has been reported in 9.5\% of patients. 4 A close relationship between Achilles tendinitis and isotretinoin dose has also been described. ${ }^{39,40}$ In our study, the patient who developed tendinitis was on low-dose isotretinoin treatment. Dose reduction and interruption can be considered in patients developing tendinitis. ${ }^{39}$ The symptoms of the patient in the current study regressed with the cessation of treatment.

The main limitations of this study include its retrospective nature and the lack of HLA-B27 assessment.

In conclusion, low back pain is one of the most common musculoskeletal side effects of isotretinoin treatment that usually resolves with dose reduction. The cumulative isotretinoin dose and increasing age are the main determinants of the severity of low back pain. Since musculoskeletal side effects are common during isotretinoin use, questioning the patients about such side effects during the treatment is essential.
Ethics Committee Approval: The study protocol was approved by the Ahi Evran University Faculty of Medicine Ethics Committee (Date 31.10.2017, no: 201716/191). The study was conducted in accordance with the principles of the Declaration of Helsinki.

Patient Consent for Publication: A written informed consent was obtained from each patient.

Data Sharing Statement: The data that support the findings of this study are available from the corresponding author upon reasonable request.

Author Contributions: Design, draft of manuscript: E.M.A.; Acquisition interpretation of data revision and approval of manuscript: S.Ş.; Design, revision and approval of the manuscript: F.A.K.

Conflict of Interest: The authors declared no conflicts of interest with respect to the authorship and/or publication of this article.

Funding: The authors received no financial support for the research and/or authorship of this article.

\section{REFERENCES}

1. Rigopoulos D, Larios G, Katsambas AD. The role of isotretinoin in acne therapy: Why not as first-line therapy? Facts and controversies. Clin Dermatol 2010;28:24-30.

2. Ott F, Bollag W, Geiger JM. Oral 9-cis-retinoic acid versus 13-cis-retinoic acid in acne therapy. Dermatology 1996;193:124-6.

3. Baykal Selçuk L, Aksu Arıca D, Baykal Şahin H, Yaylı $\mathrm{S}$, Bahadir S. The prevalence of sacroilitis in patients with acne vulgaris using isotretinoin. Cutan Ocul Toxicol 2017;36:176-9.

4. Alkan S, Kayiran N, Zengin O, Kalem A, Kimyon G, Kilinc EO, et al. Isotretinoin-induced spondyloarthropathy-related symptoms: A prospective study. J Rheumatol 2015;42:2106-9.

5. Lowenstein EB, Lowenstein EJ. Isotretinoin systemic therapy and the shadow cast upon dermatology's downtrodden hero. Clin Dermatol 2011;29:652-61.

6. Ganceviciene R, Zouboulis CC. Isotretinoin: State of the art treatment for acne vulgaris. J Dtsch Dermatol Ges 2010;8 Suppl 1:S47-59.

7. Kaplan G, Haettich B. Rheumatological symptoms due to retinoids. Baillieres Clin Rheumatol 1991;5:77-97.

8. Pedraz T, Martínez A, Pascual E. Acute hip monoarthritis in a patient treated with isotretinoin. $\mathrm{J}$ Clin Rheumatol 2006;12:105-6.

9. Nesher G, Zuckner J. Rheumatologic complications of vitamin $A$ and retinoids. Semin Arthritis Rheum 1995;24:291-6.

10. Hughes RA. Arthritis precipitated by isotretinoin treatment for acne vulgaris. $\mathrm{J}$ Rheumatol 1993;20:1241-2. 
11. Dinçer Ü, Çakar E, Kıralp MZ, Dursun H. Can isotretinoin induce sacroiliitis: Three cases. Romatizma 2008;23:157-9.

12. Bergler-Czop B, Brzezińska-Wcisło L. Proinflammatory cytokines in patients with various kinds of acne treated with isotretinoin. Postepy Dermatol Alergol 2014;31:21-8.

13. Burrage PS, Mix KS, Brinckerhoff CE. Matrix metalloproteinases: Role in arthritis. Front Biosci 2006;11:529-43.

14. Dalmolin RJ, Zanotto-Filho A, De Oliveira RB, Duarte RF, Pasquali MA, Moreira JC. Retinol and retinoic acid increase MMP-2 activity by different pathways in cultured Sertoli cells. Free Radic Res 2007;41:1338-47.

15. Sameem F, Semira. Isotretinoin-induced acute severe myopathy involving pelvic girdle muscles: A case report. Indian J Pharmacol 2016;48:601-3.

16. Stitt TN, Drujan D, Clarke BA, Panaro F, Timofeyva $\mathrm{Y}$, Kline WO, et al. The IGF-1/PI3K/Akt pathway prevents expression of muscle atrophy-induced ubiquitin ligases by inhibiting FOXO transcription factors. Mol Cell 2004;14:395-403.

17. Taheri A, Sabouhi S, Farazmand F. Incidence of low back pain and sacroiliitis in military families with acne vulgaris under isotretinoin therapy. Am J Clin Exp Immunol 2020;9:6-9.

18. Kaymak Y. Creatine phosphokinase values during isotretinoin treatment for acne. Int $\mathrm{J}$ Dermatol 2008;47:398-401.

19. Karaosmanoğlu N, Mülkoğlu C. Analysis of musculoskeletal side effects of oral Isotretinoin treatment: A cross-sectional study. BMC Musculoskelet Disord 2020;21:631.

20. Serlin RC, Mendoza TR, Nakamura Y, Edwards, KR, Cleeland CS When is cancer pain mild, moderate or severe? Grading pain severity by its interference with function. Pain 1995;61:277-84.

21. Rudwaleit M, van der Heijde D, Landewé R, Akkoc $\mathrm{N}$, Brandt J, Chou CT, et al. The Assessment of SpondyloArthritis International Society classification criteria for peripheral spondyloarthritis and for spondyloarthritis in general. Ann Rheum Dis 2011;70:25-31.

22. Türkmen D. The correlation of age, gender and drug dose with side effects of isotretinoin in patients with acne vulgaris. Turkderm - Turk Arch Dermatol Venereol 2020;54:85-9.

23. Elnady B, Elkhouly T, Dawoud NM, Desouky DE, Kewan HH, Dawoud DM, et al. New onset of axial spondyloarthropathy in patients treated with isotretinoin for acne vulgaris: Incidence, follow-up, and MRI findings. Clin Rheumatol 2020;39:1829-38.
24. Garzillo MJ, Garzillo TA. Does obesity cause low back pain? J Manipulative Physiol Ther 1994;17:601-4.

25. Bener A, Alwash R, Gaber T, Lovasz G. Obesity and low back pain. Coll Antropol 2003;27:95-104.

26. Freemont AJ, Hoyland JA. Morphology, mechanisms and pathology of musculoskeletal ageing. $J$ Pathol 2007;211:252-9.

27. De Francesco V, Stinco G, Campanella M. Acute arthritis during isotretinoin treatment for acne conglobata. Dermatology 1997;194:195.

28. Slobodin G, Rimar D, Boulman N, Kaly L, Rozenbaum M, Rosner I, et al. Acute sacroiliitis. Clin Rheumatol 2016;35:851-6.

29. Karadağ ŞG, Sönmez HE, Tanatar A, Çakan M, Aktay Ayaz N. Isotretinoin-induced sacroiliitis: Case series of four patients and a systematic review of the literature. Pediatr Dermatol 2020;37:171-5.

30. Eksioglu E, Oztekin F, Unlu E, Cakci A, Keyik B, Karadavut IK. Sacroiliitis and polyneuropathy during isotretinoin treatment. Clin Exp Dermatol 2008;33:122-4.

31. Heudes AM, Laroche L. Muscular damage during isotretinoin treatment. Ann Dermatol Venereol 1998;125:94-7.

32. Trauner MA, Ruben BS. Isotretinoin induced rhabdomyolysis? A case report. Dermatol Online J 1999;5:2.

33. Marson JW, Baldwin HE. The creatine kinase conundrum: A reappraisal of the association of isotretinoin, creatine kinase, and rhabdomyolysis. Int J Dermatol 2020;59:279-83.

34. Bettoli V, Tosti A, Capobianco C, Varotti C. Creatine kinase values during isotretinoin treatment. Dermatologica 1990;180:54-5.

35. Tillman DM, White SI, Aitchinson TC. Isotretinoin, creatine kinase, and exercise. $\mathrm{Br} \mathrm{J}$ Dermatol 1990;123:22-3.

36. Fiallo P, Tagliapietra AG. Severe acute myopathy induced by isotretinoin. Arch Dermatol 1996;132:1521-2.

37. Lawson JP, McGuire J. The spectrum of skeletal changes associated with long-term administration of 13-cis-retinoic acid. Skeletal Radiol 1987;16:91-7.

38. Ellis CN, Pennes DR, Hermann RC, Blauvelt A, Martel W, Voorhees JJ. Long-term radiographic follow-up after isotretinoin therapy. J Am Acad Dermatol 1988;18:1252-61.

39. Bottomley WW, Cunliffe WJ. Acute Achilles tendonitis following oral isotretinoin therapy for acne vulgaris. Clin Exp Dermatol 1992;17:250-1.

40. Stitik TP, Nadler SF, Foye PM, Juvan L. Greater trochanter enthesopathy: An example of "short course retinoid enthesopathy": A case report. Am J Phys Med Rehabil 1999;78:571-6. 